\title{
scripted
}

Volume 9, Issue 3, December 2012

\section{ALL THAT GLITTERS IS NOT GOLD, BUT IS IT DIAMOND?}

Daithi Mac Sithigh, ${ }^{*}$ John Sheekey ${ }^{* *}$

DOI: $10.2966 /$ scrip.090312.274

\section{(c) (i) (9)}

(C) Daithí Mac Síthigh, John Sheekey 2012. This work is licensed under a Creative Commons Licence. Please click on the link to read the terms and conditions.

\footnotetext{
* Lecturer in digital media law, University of Edinburgh: daithi.mac.sithigh@ed.ac.uk

${ }^{* *}$ Postdoctoral researcher in finite geometry, Department of Management and Engineering, Università di Padova: johnsheekey@gmail.com
} 
As 2012 comes to an end, academic authors, publishers, librarians and readers are still considering the implications of this year's 'Finch Report' ${ }^{1}$ on open access to publiclyfunded research, alongside the Government, ${ }^{2}$ Higher Education Funding Council for England $(\mathrm{HEFCE})^{3}$ and research council reactions to this report. Scholarly associations are consulting their members; speakers from research councils like the Arts and Humanities Research Council (AHRC) are frequently asked about plans for its implementation. It is therefore fitting that the editorial for this issue of SCRIPTed, a peer-reviewed open access (free to publish, free to read) journal since its foundation, addresses the Finch recommendations.

There is much to support in the report (on 'Expanding Access to Published Research Findings'), in particular the recognition that the fruits of publicly-funded research should be available to the public. The report well recognises the benefits of facilitating access to research data and outputs, in terms of the dissemination of knowledge and the encouragement of further research. It rightly points to how action has been taken in other parts of the world, and how the UK can contribute to rectifying historic imbalances and present-day exclusions through the making available of material to a global audience, particularly where users might not have access to comprehensive subscription-based resources or generous library budgets.

However, the specific recommendation of an open access 'mandate' is controversial. The report discusses two key models of open access; 'green' and 'gold'. Green open access means, in essence, that an article is available without charge to the reader through a repository (such as SSRN or an academic institution's own service), alongside the conventional subscription option. Gold, on the other hand, is where the article is available without charge to the reader from the publishing journal. However, under the gold model (at least as considered and modelled by the report), an 'article processing charge' (APC) is paid by the author to the journal. The report's recommendation is that resources be reallocated so that (in the simplest of terms) the money currently spent by UK universities on journal (electronic) subscriptions (which would be unnecessary when downloading a paper is not restricted) would instead be used to pay APCs. This model is in use in some disciplines but it is extremely rare within law; indeed, of the 156 open access law journals listed in the Directory of Open Access Journals, ${ }^{4}$ only six apply an APC. Some non-open access law journals also offer an APC option to authors, but it is rarely availed of at present.

\footnotetext{
${ }^{1}$ Working Group on Expanding Access to Published Research Findings, "Accessibility, sustainability, excellence: how to expand access to research publications" (June 2012), available at http://www.researchinfonet.org/wp-content/uploads/2012/06/Finch-Group-report-FINALVERSION.pdf (accessed 1 Dec 12).

2 Department for Business, Innovation \& Skills, "Government Response to the Finch Group Report" (16 July 2012), available at http://www.bis.gov.uk/assets/biscore/science/docs/1/12-975-lettergovernment-response-to-finch-report-research-publications (accessed 1 Dec 12).

${ }^{3}$ Higher Education Funding Council for England, "Statement on implementing open access" (2012), available at http://www.hefce.ac.uk/news/newsarchive/2012/statementonimplementingopenaccess/ (accessed 1 Dec 12).

${ }^{4}$ http://www.doaj.org (accessed 8 Dec 12)
} 
The discussion at law conferences and between legal scholars has, as a result, been dominated by the prospect of APCs being introduced. ${ }^{5}$ This is not merely a hypothetical exercise, as the Government has accepted the Finch recommendations. Indeed, one suggestion is that only works available through open access would be eligible for future Research Excellence Frameworks (REFs), and the research councils are considering how to link the award of a research grant to open access requirements. Furthermore, in many disciplines, existing scholarly associations are supported through the revenue associated with a journal, often managed on behalf of the association by a publisher. ${ }^{6}$

One factor difficult to avoid is the problematic nature of many recently launched APC supported open access journals. This has become particularly clear in the field of mathematics, where there appears to be more than a handful of publishers spotting the opportunity to generate a profit, with varying attention to academic standards. A telling demonstration of the perils of journals being financed by authors instead of readers was the acceptance (subject to an APC of £500) of a scholarly paper on "Independent, Negative, Canonically Turing Arrows of Equations and Problems in Applied Formal PDE" ${ }^{, 7}$ by the journal Advances in Pure Mathematics. ${ }^{8}$ Unfortunately for the journal (and the supposed reviewer, who recommended inter alia a clearer abstract and that "the author has better to show the specific proving processes"), the paper was automatically generated by computer software, Mathgen. ${ }^{9}$ The Chronicle of Higher Education earlier this year described the phenomenon of 'predatory' journals which are little more than vanity presses with barely credible forms of review yet strangely accommodating for rapid publication of work; ${ }^{10}$ many readers will have received their invitations through mailing lists, and a lengthy list of 'questionable' publishers has been compiled by US librarian Jeffrey Beale. ${ }^{11}$

Of course, not all APC-supported journals are predatory, and there have been some great successes in developing 'gold' journals, albeit only in some disciplines. Further developments can be observed. For example, the Forum of Mathematics (a set of

\footnotetext{
5 See for example S Bailey, "The Finch report and open access" (2012) 45 The Reporter: The Newsletter of the Society of Legal Scholars 2-3; S Bailey, “Open access: some dangers' (2012) 68 Socio-Legal Newsletter 6-7.

${ }^{6}$ See for example C Jones, "Open access publishing and the Finch report" (Royal Historical Society, letter from the President, October 2012), available at http://www.royalhistoricalsociety.org/RHSPresidentE-letterOctober2012.pdf (accessed 1 Dec 12).

${ }^{7}$ The paper was not published due to failure to pay the APC. However, it is available (without charge, and attributed to the fictional author M. Rathke) at http://thatsmathematics.com/blog/wpcontent/uploads/2012/09/mathgen-1389529747.pdf(accessed 1 Dec 12).

${ }^{8}$ http://www.scirp.org/journal/apm/ (accessed 8 Dec 12)

${ }^{9}$ N Eldredge, “Mathgen paper accepted!” (That's Mathematics! 14 September 2012), available at http://thatsmathematics.com/blog/archives/102 (accessed 1 Dec 12). See also, P Taylor, "Stochastically Orthagonal" (London Review of Books: Blog 17 October 2012), available at http://www.lrb.co.uk/blog/2012/10/17/paul-taylor/stochastically-orthogonal/ (accessed 1 Dec 12).

${ }^{10}$ B Rasmussen, “"Predatory' Online Journals Lure Scholars Who Are Eager to Publish" (Chronicle of Higher Education 4 March 2012), available at http://chronicle.com/article/Predatory-OnlineJournals/131047/ (accessed 1 Dec 12).

${ }^{11} \mathrm{http}: / /$ scholarlyoa.com/publishers// (accessed $8 \mathrm{Dec} 12$ )
} 
journals) begins publication in 2013 as an online-only 'gold' journal, published by Cambridge University Press and influenced by the campaign of Sir Timothy Gowers (mathematician and winner of the Fields Medal) against the publisher Elsevier regarding its high subscription charges. ${ }^{12}$ This journal will set "transparent" and "significantly lower than typical" APCs of around £500, waived for the first three years in anticipation of APC funding and for specified jurisdictions. ${ }^{13}$ Promises have also been made regarding possibly disadvantaged groups (e.g. early career researchers). However, the long-term viability of such an approach, particularly when associated with commercial publishers, remains unclear. There is an ethical minefield associated with the gold model. Under the currently dominant model, the editors of a journal cannot resolve financial difficulties through accepting more papers. Under gold open access, accepting an extra paper is a very tempting (and immediately beneficial) action, particularly where the core costs of an online journal (e.g. staffing) have already been covered. It is true, as Gowers' campaign and the Finch report have demonstrated, that there are sharp practices regarding 'bundling' of journals and pricing strategies. However, while gold open access might mitigate some of those issues, it is a mistake to see this model as the only solution.

Although not considered in detail in the Finch report, nor in the resulting proposals for implementation, there is an alternative. The Australian mathematician John Bamberg discusses this form of 'diamond' open access (taking a term coined by Marie Farge, a mathematician at the Centre National de la Recherche Scientifique), where no fee is charged either to author or reader. ${ }^{14}$ SCRIPTed and indeed most of the open access journals in law (such as the well-established German Law Journal, ${ }^{15}$ the recently re-launched European Journal of Law \& Technology ${ }^{16}$ and the new feminists@law ${ }^{17}$ ) follow this model. An editorial not unlike the present one in a recent issue of feminists@law describes the model as 'platinum' and praised it. ${ }^{18}$ In mathematics, Bamberg points to the Electronic Journal of Combinatorics (in its $19^{\text {th }}$ annual volume), and subsequently, the well-established Australian scholarly association Combinatorial Mathematics Society of Australia announced that the $58^{\text {th }}$ volume onwards of its Australian Journal of Combinatorics would be published in this way. ${ }^{19}$

\footnotetext{
${ }^{12} \mathrm{~T}$ Gowers, “A new open-access venture from Cambridge University Press" (Gowers's Weblog 2 July 2012), available at http://gowers.wordpress.com/2012/07/02/a-new-open-access-venture-fromcambridge-university-press (accessed 1 Dec 12); T Gowers, "Elsevier: my part in its downfall" (Gowers's Weblog 21 January 2012), available at http://gowers.wordpress.com/2012/01/21/elseviermy-part-in-its-downfall/ (accessed 1 Dec 12).

${ }^{13}$ Cambridge University Press, "Forum of Mathematics: FAQs" (19 November 2012), available at http://journals.cambridge.org/images/fileUpload/images/FAQs_19-11-2012.pdf (accessed 1 Dec 12).

14 J Bamberg, "Green, gold or diamond access" (SymOmega 9 August 2012), available at http://symomega.wordpress.com/2012/08/09/green-gold-or-diamond-access/ (accessed 1 Dec 12).

${ }^{15} \mathrm{http}: / /$ www.germanlawjournal.com (accessed 8 Dec 12)

${ }^{16}$ http://ejlt.org (accessed 8 Dec 12)

${ }^{17}$ http://journals.kent.ac.uk/index.php/feministsatlaw (accessed 8 Dec 12)

${ }^{18}$ R Hunter, D Alessandrini \& T Williams, "Why we oppose gold open access" (2012) 2(2) feminists@law, http://journals.kent.ac.uk/index.php/feministsatlaw/article/view/59/179 (accessed 1 Dec 12)

${ }^{19}$ http://ajc.maths.uq.edu.au (accessed 8 Dec 12)
} 
It is hardly in doubt that the cost of journal subscriptions, whether to UK university libraries or individual researchers far beyond these borders, is significant. It is reasonable to wonder whether the money currently spent on these subscriptions out of UK public resources is appropriate. However, the Finch proposals, but more so the way in which they have been taken up by Government, present a risk that the cure would be at least as harmful as the illness. Concerns that a move to APCs would reinforce existing imbalances in higher education were hardly soothed by the September decision to allocate transitional open access funding to the 'top 30' institutions only (measured in terms of existing grant income). ${ }^{20}$ In some disciplines, where much research is as a matter of course the result of specifically funded projects with high budgets, APCs may be absorbed as just another cost alongside academic time, equipment, field trips and so forth. In others, where research can be the result of academic time alone, this is a new and not insignificant cost; the mathematician or legal scholar is with good reason more anxious than some in the physical and biomedical sciences might be.

Other issues remain unaddressed. What answer should be given to a Head of School who wonders what to 'do' with a scholar who produces good research after the money for APCs has been spent; it is much easier to understand a fixed ceiling on library spending than it is to make sense of one on publication. (The consequences of decisions on whether an author is allowed to publish being a matter for university treasurers must also be noted with some trepidation). The impact of rises in APCs will be worth watching; should an affected researcher publish fewer articles, or move to 'cheaper' journals? Most recently, the research councils have announced the planned scheme for supporting gold open access in respect of RCUK-funded research, through a block grant to institutions, based on the model of an average APC of $£ 1727$ excluding VAT per article) to be rolled out over the coming years. ${ }^{21}$

With this in mind, it is reasonable to wonder why proper consideration is yet to be given to promoting diamond or platinum open access, perhaps as part of a 'mixed economy' of academic publication. Simply shifting subscription budgets to APCs reassures publishers of continued income, and may entail some benefits for readers (subject to clarification regarding back issues, of course). However, we argue that it has the potential to harm academic research, particularly in disciplines like law and mathematics. If even a fraction of the overall proposed spending on APCs by the Research Councils, HEFCE and others was allocated to supporting the management costs of diamond open access journals (this already happens unofficially in practice through research centres and institutional allocation of funds in certain cases), all of the benefits of Finch would be supported, but in a context of high standards and academic freedom. Finch could have called for a 'Public Journal' model, which would not exclude the involvement of professional editors and publishers, but would counteract the negative features of the subscription model without the distributive, disciplinary and ethical weaknesses of gold open access. Institutions can also play a

\footnotetext{
${ }^{20}$ P Jump, “Government pledges $£ 10$ million to aid open-access move" (Times Higher Education 7 September 2012), available at http://www.timeshighereducation.co.uk/story.asp? storycode $=421081$ (accessed 1 Dec 2012).

${ }^{21}$ Research Councils UK, "RCUK announces block grants for universities to aid drives to open access to research outputs" (8 November 2012), available at http://www.rcuk.ac.uk/media/news/2012news/Pages/121108.aspx (accessed 1 Dec 12).
} 
supportive role, as some already do, through rewarding participation by academic and administrative staff in diamond open access journals through workload allocation and promotion. This would make a meaningful contribution to 'engagement' and 'impact' agendas, as well as to the wider objective of increasing access to knowledge in perpetuity. Perhaps, it is worth reminding Government and the research councils, in this year of the $50^{\text {th }}$ anniversary of the James Bond film series, that diamonds are forever. 